\title{
Agôn
}

Revue des arts de la scène

Critiques | Saison 2016-2017

\section{Avignon, 22 juillet : Les Grands, texte de Pierre Alferi, conception de Fanny de Chaillé}

Parler de soi

\section{Caroline Châtelet}

\section{(2) OpenEdition}

\section{Journals}

Édition électronique

URL : http://journals.openedition.org/agon/4019

DOI : 10.4000/agon.4019

ISSN : 1961-8581

Éditeur

Association Agôn

Référence électronique

Caroline Châtelet, « Avignon, 22 juillet : Les Grands, texte de Pierre Alferi, conception de Fanny de Chaillé ", Agôn [En ligne], Critiques, mis en ligne le 22 juillet 2017, consulté le 23 septembre 2020. URL : http://journals.openedition.org/agon/4019 ; DOI : https://doi.org/10.4000/agon.4019

Ce document a été généré automatiquement le 23 septembre 2020.

Association Agôn et les auteurs des articles 


\title{
Avignon, 22 juillet : Les Grands, texte de Pierre Alferi, conception de Fanny de Chaillé
}

Parler de soi

\author{
Caroline Châtelet
}

\section{RÉFÉRENCE}

Les Grands, texte de Pierre Alferi, conception de Fanny de Chaillé, du 19 au 20 juillet, Théâtre Benoît XII, Festival d'Avignon In.

1 Il est toujours étonnant de constater comment certaines œuvres nourrissent (plus ou moins souterrainement) la réflexion, accompagnent, résonnent face à d'autres. Concernant l'enfance, deux documentaires, aux antipodes formels l'un de l'autre reviennent - à tel point que je les cite de loin en loin ici ${ }^{1}$ ou là $^{2}$. Tandis que Disneyland, mon vieux pays natal d'Arnaud des Pallières (sorti en 2001) est proche d'un cinéma expérimental, Récréation de Claire Simon est d'une facture plus classique. Dans ce film réalisé en 1993, Claire Simon filme des enfants dans une cour d'école maternelle. À leur hauteur, au plus près de leurs jeux et discussions. Ce qui rend cette œuvre belle, saisissante, c'est sa position sans surplomb. Un adulte regarde des enfants. Peut-être, les regardant, réalise-t-elle l'écart entre leurs usages et les siens. En tous les cas, elle nous les donne à voir, à nous adultes, nous renvoyant à ce que nous sommes et ce que nous ne sommes plus. Dans Les Grands, c'est notamment cela que met au travail Fanny de Chaillé. Pour cette nouvelle création, la chorégraphe collabore pour la troisième fois avec Pierre Alferi. Connu pour avoir fondé avec Olivier Cadiot l'éphémère mais vivace Revue de littérature générale au mitan des années 90, ainsi que pour ses positions politiques (il a notamment critiqué l'état d'urgence en 2015 et soutenu le mouvement Nuit debout au printemps 2016), Pierre Alferi développe une œuvre travaillée par les questions de fond et de forme. 
2 Pour Les Grands, Pierre Alferi a ajusté le texte au fil des échanges avec Fanny de Chaillé et les interprètes. Comme l'a justement défini le journaliste Arnaud Laporte lors de la conférence de presse au Festival d'Avignon ${ }^{3}$, la proposition suit une forme «ternaire » : si neuf interprètes sont au plateau, ils incarnent trois personnages. Une femme, deux hommes, à des âges différents (enfant, adolescent, adulte), la variation de motifs ou de couleurs (plus ou moins intense) de leur costume signalant leur avancée en âge. Entrant en scène progressivement et dans un ordre croissant, ces personnages évoluent sur un plateau blanc, white cube occupé par trois strates de sédimentation géologique de tailles différentes. Trois personnages, trois tranches d'âge, trois espaces scénographiques, et trois positions d'énonciation. Les enfants se déplacent et demeurent muets, leur parole diffusée en voix off nous renvoyant à la contemplation, au rêve. Les adolescents sont dans un premier temps muets, "parlés " par les adultes qui s'expriment pour eux au micro, puis ils se révoltent et prennent eux-mêmes la parole. Autonomes, les adultes ont leur voix et leur corps. A cette dissociation corps-voix et au dispositif spécifique pour chaque tranche d'âge répondent les préoccupations propres à chacun. Les jeux infinis que l'on s'invente pour les enfants, les premiers émois amoureux et la confrontation avec l'autorité, l'interrogation sur l'avenir pour les adolescents, la façon de composer avec le monde et l'adresse des adultes aux enfants pour les adultes. Si certains moments tendent à chercher le rire de façon trop volontariste - telle la caricature du slow ou le choix de Guillaume Bailliart d'imiter une mue de voix l'interprétation des comédiens, la circulation d'un âge à un autre est émouvante, ainsi que très pertinente. D'un âge et d'une position d'énonciation à l'autre, c'est le regard d'adultes sur leurs vies qui se déploie. Employée par les enfants pour désigner les adultes, Les Grands est, aussi, l'expression des adultes lorsqu'ils s'adressent à des enfants. Cette ambigüité (qui parle à qui ? Qui s'adresse à qui ?) signale la particularité de ce projet: des quarantenaires - comme le disent certaines références, notamment un morceau musical de Radiohead - regardent où ils en sont en tant qu'adultes et tentent de retraverser ou de se remémorer les états de l'enfance. L'enfant et l'adolescent ne sont ici pas considérés comme des adultes en devenir, mais comme des êtres traversés de leurs propres logiques dont nous pourrions apprendre. Dans ce dispositif, les adresses finales ne sont pas tant destinées aux jeunes qu'à nous, adultes présents dans la salle. Intitulées ironiquement « Cours sur l'âge adulte à l'adresse des nouvelles générations » ces discours se clôturent sur un stimulant encouragement à jouer, non pas pour gagner mais pour perdre, pour démonter les modèles, et refuser un système obligatoirement marchand.

3 Et puis, par sa forme même, c'est à une passionnante réflexion sur le théâtre que Les Grands renvoie. Car ce geste de ventriloquie, ce trouble de l'énonciateur constitue l'interrogation fondamentale de tout projet théâtral: est-ce le metteur en scène, l'auteur, le comédien ou son personnage qui parlent ? Et en tant que spectateur, qu'estce que je vois, qui/qu'est-ce que je crois? 


\section{NOTES}

1. Voir l'entretien avec Claire Simon et Théodore Collatos : http://www.flux4.com/entrevues/ entrevues-2012/883-entrevues-2012-emission-avec-claire-simon-et-theodore-collatos.html 2. Voir l'article dans la revue Novo : https://issuu.com/media.pop/docs/novo_45/76

3. Voir la Conférence de Presse de Fanny de Chaillé et Pierre Alferi : https://www.theatrevideo.net/video/Fanny-de-Chaille-pour-Les-Grands-71e-Festival-d-Avignon?autostart 